\title{
EFFECTIVENESS OF USAGE OF STRAW AND OAK LEAVE PELLETS FOR BIOGAS PRODUCTION
}

\author{
Atis Klavins, Vilis Dubrovskis, Imants Plume \\ Latvia University of Life Sciences and Technologies, Latvia \\ atisklavins87@gmail.com, vilisd@inbox.lv,imants.plume@1lu.lv
}

\begin{abstract}
Biogas and methane can be obtained from various biomasses, and biogas producers should focus on usage of agricultural by-products and forest residues to replace or minimise the specially cultivated energy crops, e.g. maize, usage as the feedstock in biogas plants. In order to evaluate the effectiveness of use of wheat straw and oak leaves for biogas production, the experimental trial on wheat straw and oak leave pre-treatment and following anaerobic fermentation was provided. Pre-treatment of straw and leaves for biogas production included the common mechanical treatment by shredding and milling. Part of the straw, leaves and their mixture was further granulated to determine the energy consumption of the granulation process and to explore their potential for biogas production. The investigated energy for pelletting the wheat straw, oak leaves or straw/leaves (1:3) mixture was $2.00,0.20$ or $0.22 \mathrm{kWh} \mathrm{kg}^{-1}$ respectively. The anaerobic fermentation (AF) of residue biomass was provided in 16 batch bioreactors with volume $0.75 \mathrm{~L}$, operated during 40-day period at temperature $38 \pm 1{ }^{\circ} \mathrm{C}$. Average specific biogas (methane) yield from wheat straw or oak leaves was 0.618 (0.246) $\mathrm{L} \cdot \mathrm{g}_{\text {DOM }}^{-1}$ or $0.254(0.151) \mathrm{L}_{\mathrm{g}} \mathrm{g}_{\text {DOM }}^{-1}$ respectively. Average biogas (methane) specific yield from the straw/leaves (3:1) mixture or straw/leaves $(3: 1)$ pellets was $0.236(0.155) \mathrm{L}^{-\mathrm{g}^{-1} \text { DOM }}$ or $0.322(0.191) \mathrm{L} \cdot \mathrm{g}^{-1}$ DOM respectively. Usage of straw/leaves (1:3) pellets increases the specific methane yield by $22.3 \%$ compared to specific methane yield obtained from non-pelletized straw/leaves $(3: 1)$ mixture.
\end{abstract}

Keywords: anaerobic digestion, methane, wheat straw, oak leaves, pellets.

\section{Introduction}

Nowadays strategy is to develop the use of alternative energy sources instead of fossil fuels to offset current energy needs, so providing the further reducing of environmental problems caused by pollution and global warming. The benefits of biogas production in the anaerobic fermentation (AF) process are not only financial. It has a number of different positive effects, many of which are most directly related to environment preservation. The most important effect is the reduction of emissions of methane, which is released from manure storages and contributes to the greenhouse gas (GHG) effect. "Agriculture is the second largest emitter in Latvia's GHG inventory, accounting for $24.6 \%$ $\left(2782.32 \mathrm{kt} \mathrm{CO}_{2}\right.$ eq) of Latvia's total GHG emissions in 2017. Manure management accounted for $6.8 \%$, while liming and urea combined accounted for $1.2 \%$ of total agricultural emissions in 2017" [1].

Reported emissions from livestock buildings from $1 \mathrm{LU}$ (livestock unit $=500 \mathrm{~kg}$ ) for $\mathrm{CH}_{4}$, the median of emission factors for dairy cows $\left(302.5 \mathrm{~g} \cdot \mathrm{day}^{-1} \cdot \mathrm{LU}^{-1}\right)$ was more than three times higher than the value for pigs $\left(85 \mathrm{~g} \cdot \mathrm{day}^{-1} \cdot \mathrm{LU}^{-1}\right)[2]$.

Livestock manure use in the AD process is the most cost effective measure for reducing of GHG (greenhouse gases) emissions compared to combined use of manure and energy crops in biogas cogeneration plant. Italian researchers reported that to achieve the reduction of 1 tons $\mathrm{CO} 2$ eq, plant $\mathrm{B}$ (totally fed with animal slurries) is granted with about $100 €$, while to achieve the same reduction the bigger plants required an amount of subsidy that is from 56 (Plant D) to about 600 (Plant C) times higher [3]. Replacement of the energy crops, e.g. maize silage, with the straw or other residues can significantly improve the economic and environmental performance of the agricultural biogas plants.

Also, burning of crop residues on field leads to the emission of a number of atmospheric pollutants: ammonia (NH3), oxides of nitrogen (NOx), non-methane volatile organic compounds (NMVOCs), sulphur dioxide (SO2), carbon monoxide (CO), heavy metals (HM), dioxin and particulate matter (PM) including black carbon ( $\mathrm{BC} 1)$ [4]. By producing electricity and/or heat from manure and crop residues, methane is burned and resulting exhaust gases is less harmful for environment compared to straw open burning or burning in unsuitable furnaces. As the carbon and hydrogen only escape in biogas, the finished digestate produced in the AF process contains all plant nutrients, e.g., nitrogen, phosphorus, potassium and micronutrients.

Most of biogas plants in Latvia use maize silage as the main substrate component traditionally, and very few utilise the easy available cereal straw or forest residue for increase of the biogas yield 
and stability of feedstock supply. Straw and tree leaves (collected in fall season) have high lignin content and, therefore, have a long fermentation period.

To overcome these problems, special pre-treatment methods of straw or tree leaves have been investigated by many researchers. If high content of lignocellulosic material (e.g. straw) is digested, often a separate hydrolysis tank with lower temperatures (e.g. $25-35^{\circ} \mathrm{C}$ ) is included [5].

Pre-treatment of wheat straw with alkaline materials at different temperature was reported by researchers. The lignocellulosic material was separately pretreated using i) the organic solvent $\mathrm{N}$ methylmorpholine N-oxide (NMMO) at $120^{\circ} \mathrm{C}$ for $3 \mathrm{~h}$, ii) the organosolv method, employing ethanol as the organic solvent at $180{ }^{\circ} \mathrm{C}$ for $1 \mathrm{~h}$ and iii) using an alkaline pretreatment with $\mathrm{NaOH}$ at $30{ }^{\circ} \mathrm{C}$ for $24 \mathrm{~h}$. All the pretreatments were effective in increasing the biomethane production yield of wheat straw. In particular, the cumulative biomethane production yield of $274 \mathrm{~mL} \mathrm{CH} 4 \mathrm{~g}^{-1}$ VS obtained with the untreated feedstock was enhanced by $11 \%$ by the NMMO pretreatment and by $15 \%$ by both the organosolv and alkaline pretreatment [6].

Other researchers investigated anaerobic co-digestion of microalgal biomass grown in wastewater and wheat straw. The results showed that the methane yield was increased by $77 \%$ with the codigestion as compared to microalgae mono-digestion, while the pretreatment only increased the methane yield by $15 \%$ compared to the untreated mixture. Thus, the anaerobic co-digestion of microalgae and wheat straw was successful even without applying thermo-alkaline pretreatment [7].

Chinese researchers investigated the lignocelluloses biodegradation by microbial consortium composed of bacteria and fungi. A pretreatment of lignocelluloses by using this functional microbial consortium was designed and results showed that enhanced degradability in wheat straw and the broth containing amounts of organic materials (e.g. volatile fatty acids and carbohydrates) that could be used for biogas synthesis were detected in the pretreatment system. A subsequent anaerobic fermentation with the application of the pretreated system showed a $39.24 \%$ and $80.34 \%$ increase in total biogas and methane yield, as well as a faster startup in a 20 day production process compared to the process based on the untreated system [8].

Relatively new method is the use of biomass pellets as the feedstock for anaerobic fermentation. Our previous research shows relatively high biogas and methane yields obtainable from straw pellet co-fermentation with molasses and sunflower oil. Average biogas yield from co-fermentation of wheat straw pellets and molasses was $0.777 \mathrm{~L} \cdot \mathrm{g}^{-1}$ DOM and the methane yield was $0.408 \mathrm{~L} \cdot \mathrm{g}^{-1}$ DOM. Average biogas yield from fermentation of wheat straw pellets with $1 \mathrm{~mL}$ Metaferm was $0.692 \mathrm{~L} \cdot \mathrm{g}^{-1}$ DOM and the methane yield was $0.349 \mathrm{~L} \cdot \mathrm{g}^{-1}$ Dom. Average biogas yield from co-fermentation of wheat straw pellets and sunflowers oil was $1.041 \mathrm{~L} \cdot \mathrm{g}^{-1}$ DOM and the methane yield was $0.639 \mathrm{~L} \cdot \mathrm{g}^{-1}$ DOM [9].

However, the mentioned above technologies require increased energy, chemicals or special microbiological inoculums input so compromising the economic feasibility of biogas production from lignocellulosic biomass. Further research should be provided to evaluate economic feasibility on codigestion of different locally available biomasses providing acceptable methane production and environmental utilisation of agricultural and municipal residues. Traditionally, fallen leaves from trees growing in parks, squares, streets and roadsides in towns are collected in heaps for further transportation to landfills. However, the leave biomass in heaps moistened by rain was biodegraded by aerobic microorganisms releasing greenhouse gases (GHG) in environment. Also, transportation of loose leaves to landfills is connected with high specific fuel consumption releasing lot of GHG additionally. Anaerobic digestion of leaves or co-digestion with other waste biomass can minimise such environmental pollution and provide the option for environmental management.

The purpose of the current research is to investigate the anaerobic fermentation process of wheat straw and oak leaves (OL), and their mixtures in form of powders or pellets.

\section{Materials and methods}

For experimental purposes, fallen oak leaves (OL) were collected in October 2019, in town Jelgava. Wheat straw (WS) was obtained from the farm "Snēpeles", Saldus region, in August 29, 2019 in dry and sunny weather, just after the harvesting of cereals. The biomass materials were pre-treated by mechanical grinding, hammer milling and sieving through a $2.0 \mathrm{~mm}$ mesh sieve, to obtain homogeneous material with the particle size of 2-3 mm, Fig. 1 and Fig. 2. 


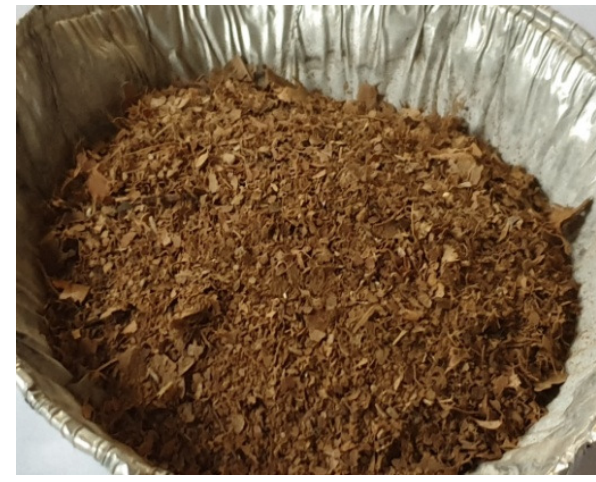

Fig. 1. Oak leave biomass

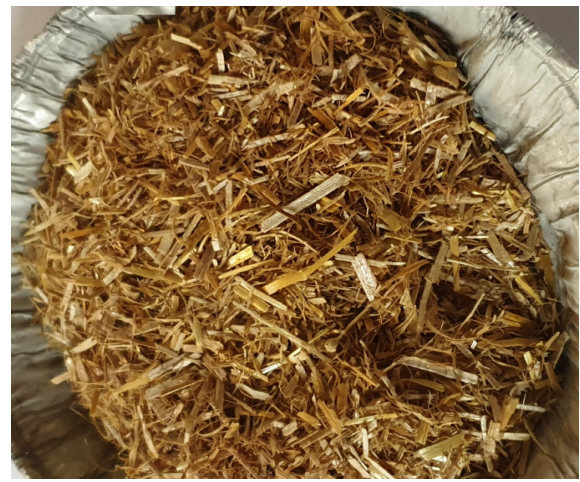

Fig. 2. Wheat straw biomass

Part of oak leaf (OL) and wheat straw (WS) biomass then was mixed together to form a leaf: straw (3:1) mixture (LSM). Portion of the leave and straw (3:1) mixture was processed in a pelletizing unit (model 2L6P150B) having a forming disk with holes in diameter of $6 \mathrm{~mm}$ (Fig. 3) to produce the leaf-straw pellets (LSP), Fig. 4.

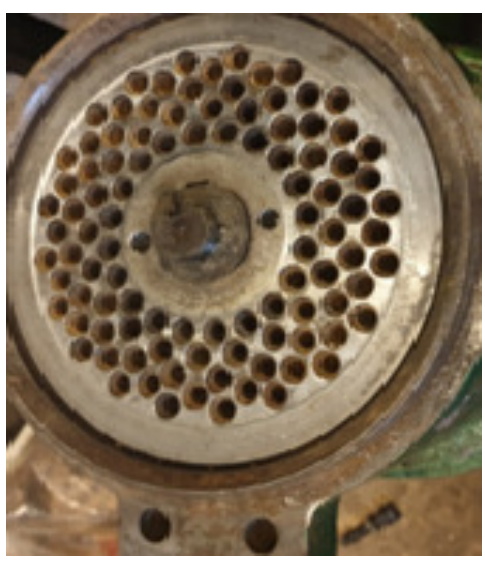

Fig. 3. Disc of pelletizer 2L6P150B

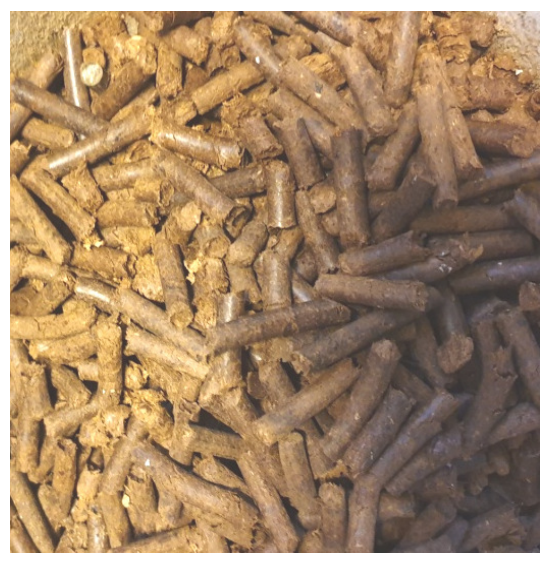

Fig. 4. Leaves-straw (3:1) pellets (LSP)

During the pelletization process, the pelletizer motor (type Y112M-4) was connected to the mains through the electricity meter (model G3B145, accuracy $\pm 2.0 \%$ ) to determine the energy consumption.

Biomass and substrate weight was determined before mixing or the pelletization process by scales (model KFB $16 \mathrm{KO} 2$, accuracy $\pm 0.2 \mathrm{~g}$ ). Before anaerobic fermentation, the samples of raw biomass were analysed to determine the total solids (TS) and dry organic matter (DOM) content in biomass, to plan the appropriate substrate organic load in every bioreactor.

Total solids (TS) content in samples was determined by drying of a sample in thermostat-weights (model MOC-120H, accuracy of weight measurements $\pm 0.001 \mathrm{~g}$ ) at $105^{\circ} \mathrm{C}$. Dry organic matter (DOM) content was obtained using the oven (model Memmert) at $550{ }^{\circ} \mathrm{C}$ for aching of dry samples according to a standard aching cycle. Calculation of the sample TS and DOM content in the sample was provided using standard mathematical operations. According to the experimental plan, substrates were filled in $0.75 \mathrm{~L}$ bioreactors, forming groups of bioreactors with similar substrates within each group for statistical reliability. Design and implementation of the experimental plan was based on standard experimental methods developed by German researchers [10].

All 16 bioreactors were filled with $500 \mathrm{~g}$ inoculums (finished cows manure digestate) to provide microbial community, necessary for providing of a stable anaerobic fermentation (AF) process. Control bioreactors R1; R16 were filled with $500 \mathrm{~g}$ inoculums only to investigate the amount of biogas and methane released from pure inoculums. In bioreactors R2-R15 were added researchable biomaterials for investigation of methane potential during the AF process. At the end of the AF process, average biogas and methane volumes from pure inoculums were subtracted from the volumes of biogas and methane obtained from bioreactors R2-R15 to calculate respective gas volumes released only from added biomass in substrate. After positioning of all bioreactors in the thermostat, at same 
time, the anaerobic fermentation (AF) process was provided in the batch process at temperature $38 \pm 0.5{ }^{\circ} \mathrm{C}$ until gas emission ceases. For gas collection, gas bags are connected to outlets of bioreactors and positioned outside of thermostat, providing regular analyses of the gas volume and composition using the gas flow meter (Ritter drum-type) and gas analyser (model Gasboard 3200L) respectively. Substrate $\mathrm{pH}$ value was measured in the bioreactor before and after the AF process, using the $\mathrm{pH}$ meter (model HI 8424, accuracy \pm 0.01 ).

After the gas emission from bioreactors ceases, all substrates were weighted and total solids and dry organic matter content determined, using the above mentioned methods and common mathematical operations for calculation of the coefficient of degradation of added biomass during the AF process.

\section{Results and discussion}

The process duration and energy consumption for biomass pelletization are given in Table 1.

Process duration and energy consumption for pellets production

Table 1

\begin{tabular}{|l|c|c|c|c|c|}
\hline $\begin{array}{c}\text { Raw material, } \\
\mathbf{~ k g}\end{array}$ & $\begin{array}{c}\text { Weight, } \\
\mathbf{k g}\end{array}$ & $\begin{array}{c}\text { Process, } \\
\mathbf{m i n}\end{array}$ & $\begin{array}{c}\text { Reading start, } \\
\mathbf{k W h}\end{array}$ & $\begin{array}{c}\text { Reading, end, } \\
\mathbf{k W h}\end{array}$ & $\begin{array}{c}\text { Eenergy, } \\
\mathbf{K W h} \cdot \mathbf{k g}^{-1}\end{array}$ \\
\hline Wheat straw & $1.0 \pm 0.02$ & 16.04 & 50815.3 & 50817.30 & 2.00 \\
\hline Oak leaves & $1.0 \pm 0.02$ & 3.45 & 50817.6 & 50817.80 & 0.20 \\
\hline Leaves + straw $(3+1)$ & $0.9 \pm 0.02$ & 3.12 & 50818.0 & 50818.20 & 0.22 \\
\hline
\end{tabular}

Strong lignocellulosic fibres of straw require the most time and energy to make pellets from the straw biomass. Specific energy for the oak leave pellets or leaves/straw (3:1) pellet production is only $10 \%$ or $11 \%$, respectively, of the specific energy consumed for wheat straw pellet production.

This can be explained by the weak leaf biomass resistance to breaking, as well as by the "oily" properties of the leaf biomass facilitating pelletisation of the leaf-straw mixture.

Composition of substrates, weight and content of dry organic matter (DOM) in substrates before anaerobic digestion is shown in Table 2.

Table 2

Results of analyses of raw material before anaerobic digestion

\begin{tabular}{|c|c|c|c|c|c|c|c|}
\hline Reactor & $\begin{array}{c}\text { Raw } \\
\text { material }\end{array}$ & $\begin{array}{c}\text { Weight, } \\
\mathbf{g}\end{array}$ & $\begin{array}{c}\text { TS, } \\
\mathbf{\%}\end{array}$ & $\begin{array}{c}\text { TS, } \\
\mathbf{g}\end{array}$ & $\begin{array}{c}\text { ASH, } \\
\mathbf{\%}\end{array}$ & $\begin{array}{c}\text { DOM, } \\
\mathbf{\%}\end{array}$ & $\begin{array}{c}\text { DOM, } \\
\mathbf{g}\end{array}$ \\
\hline R1; R16 & IN & 500 & 4.60 & 23.00 & 0.37 & 4.23 & 21.15 \\
\hline R2-R4 & WS & $20^{*}$ & 88.37 & 17.67 & 4.52 & 83.84 & 16.77 \\
\hline R5-R7 & OL & $20^{*}$ & 86.50 & 17.30 & 16.30 & 70.18 & 14.040 \\
\hline R8-R11 & OSM & $20^{*}$ & 86.97 & 17.39 & 13.36 & 73.61 & 14.720 \\
\hline R12-R15 & OSP & $20^{*}$ & 91.86 & 18.37 & 10.77 & 81.08 & 16.217 \\
\hline R2-R4 & IN + WS & 520 & 7.82 & 40.67 & 0.53 & 7.29 & 37.92 \\
\hline R5-R7 & IN + OL & 520 & 7.75 & 40.30 & 0.98 & 6.77 & 35.183 \\
\hline R8-R11 & $\begin{array}{c}\text { IN + OS } \\
\text { M }\end{array}$ & 520 & 7.77 & 40.39 & 0.87 & 6.90 & 35.866 \\
\hline R12-R15 & IN + OSP & 520 & 7.96 & 41.37 & 0.77 & 7.19 & 37.363 \\
\hline
\end{tabular}

Note: IN - inoculum; OL - oak leaves; - wheat straw; LSM - leaves (15 g) + straw (5 g) mixture; LSP - leaves $(15 \mathrm{~g})+$ straw (5 g) pellets; ASH - ashes; TS - total solids; DOM - dry organic matter (on raw substrate basis); R1;R16 - bioreactors with inoculums only (control bioreactors); R2-R4 group of bioreactors with similar substrates composition; * - Weight of added biomass (without inoculums) in every substrate within group of bioreactors.

Raw material analyses show that the straw (WS) biomass has higher dry organic matter (DOM) content, and oak leaves (OL) have lower DOM content, as the OL were picked up in late autumn and lost part of organic matter in the natural biodegradation process.

After finishing of the AF process, digestate analyses were provided to obtain DOM content in digestate from every bioreactor, to calculate total degraded organic matter in every bioreactor. 
Biodegradation of added organic matter in each bioreactor (with added biomass) was calculated by subtracting the average degraded organic matter of inoculums in control bioreactors (R1; R16).

The highest average percentage of biodegradation $57.62 \%$ was found for wheat straw organic matter, and lower percentage of biodegradation $28.8 \%$ was found for oak leave (OL) organic matter. This evidence may be explained by the fact that OL biomass has relatively low DOM content at the start of the AF process. Biogas and methane yields obtained in the AF process from all reactors with added biomass are shown in Fig. 5.

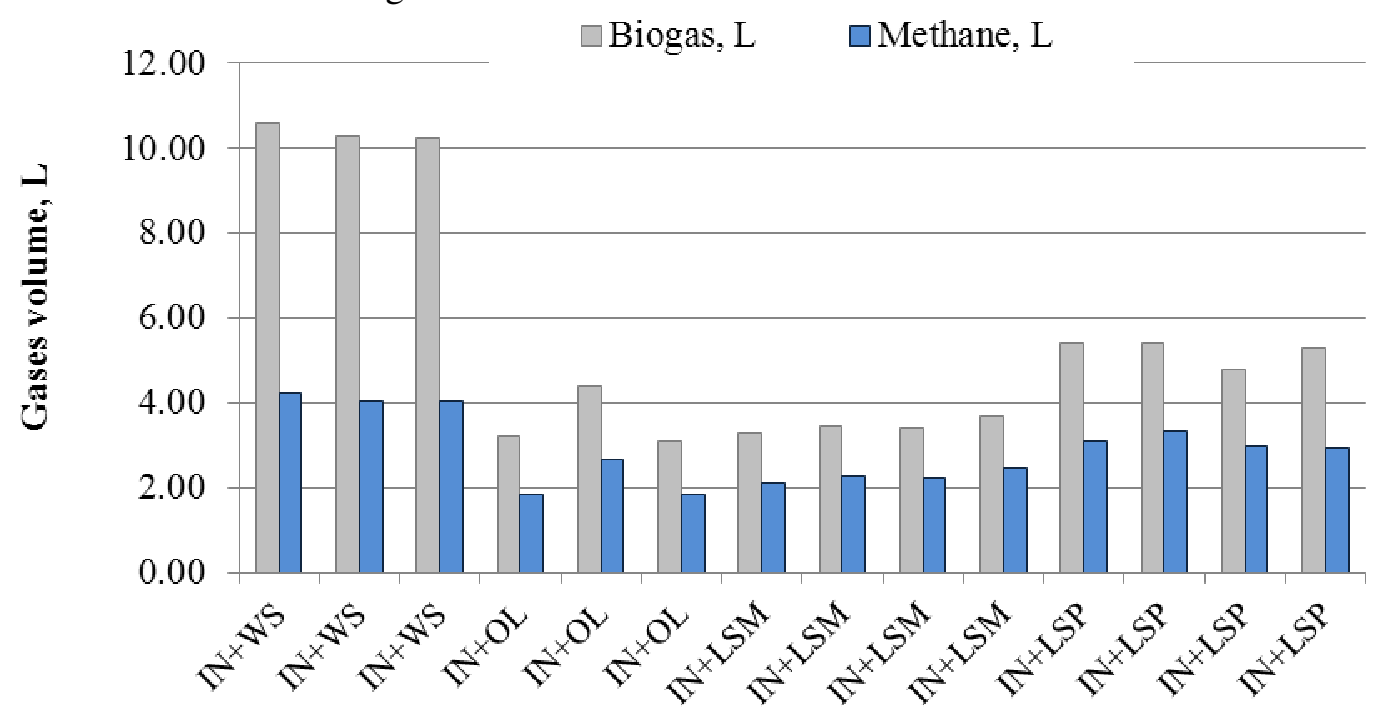

\section{Substrate in bioreactor}

Fig. 5. Biogas and methane yields from all reactors with added biomass: IN - inoculums;

WS - wheat straw; OK - oak leaves; LSM - leaves/straw (3:1) mixture; LSP - leaves/straw (3:1) pellets

The experimental data show the highest biogas and methane yields in bioreactors with added wheat straw biomass, and lower biogas and methane yields in bioreactors with oak leave biomass.

Low methane yields from oak leaves can be explained by the high content in lignocelluloses in the oak leave biomass, as well as by high carbon/nitrogen ratio. Also, some substances in oak leaves may inhibit activity of the microbial activity in the substrate. Further research with co-fermentation of oak leaves with nitrogen rich materials, e.g. manure, wastewater sediments, should be provided.

Specific biogas and methane volumes per unit of added biomass dry organic matter (DOM) are given in Fig. 6.

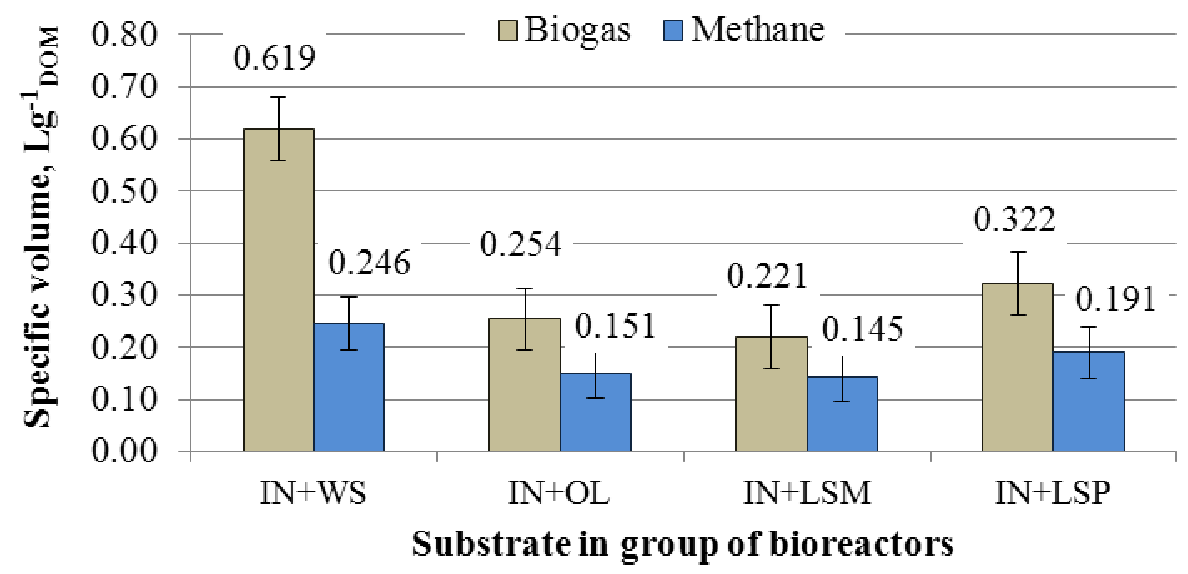

Fig. 6. Average specific biogas and methane volumes for groups of bioreactors with similar substrates: IN - inoculums; WS - wheat straw; OK - oak leaves; LSM - leaves/straw (3:1) mixture; LSP - leaves/straw $(3: 1)$ pellets 
The investigated average specific biogas (methane) volume $0.619(0.246) \mathrm{L} \cdot \mathrm{g}^{-1}$ DOM from wheat straw is comparable with the average specific biogas (methane) yield $0.540(0.285) \mathrm{L} \cdot \mathrm{g}^{-1}$ Dom obtained in earlier research from anaerobic fermentation of wheat straw pellets [9]. Also, the obtained specific methane volume is similar to the specific methane volume $0.240 \mathrm{~L} \cdot \mathrm{g}^{-1}$ DOM , when wheat straw alone was used as the substrate during anaerobic fermentation with digestate liquor recycling [11].

Lower average specific biogas (methane) volume $0.256(0.156) \mathrm{L} \cdot \mathrm{g}^{-1}$ DOM is observed in gases from bioreactors with added oak leave biomass. This evidence can be explained by specific substances in oak leaves inhibiting the microbial activity in the substrate.

Methane content in biogas from bioreactors with added researchable biomass is shown in Fig. 7.

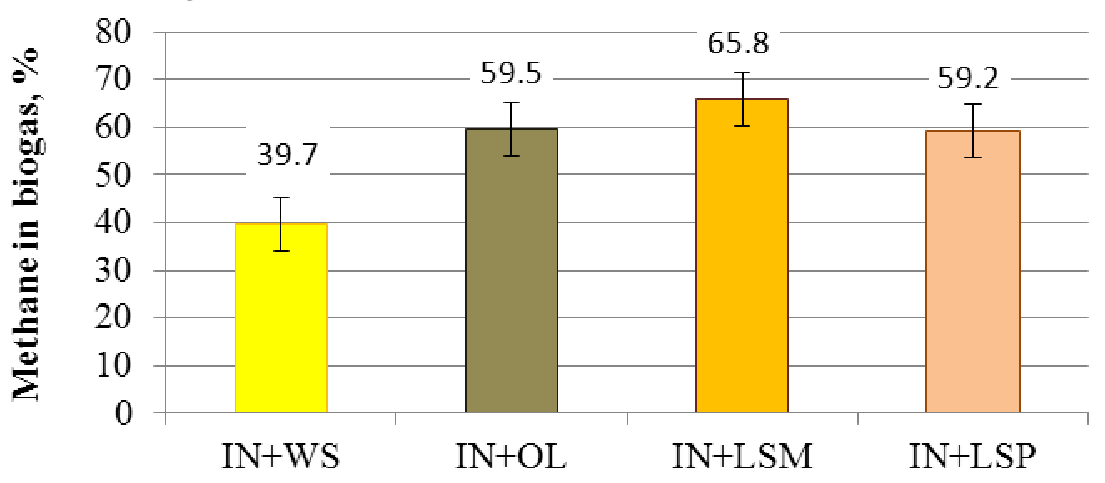

Substrate in group of bioreactors

Fig. 7. Average methane content in biogas in groups of bioreactors with added biomass:

IN - inoculums; WS - wheat straw; OK - oak leaves; LSM - leaves/straw (3:1) mixture; LSP - leaves/straw (3:1) pellets

High average methane content was obtained in biogas from the leaves-straw mixture. It can be explained by favourable bacteria community developed in this group of bioreactors due to the cofermentation effect of straw-pellet mixture together with inoculums still having relatively high organic matter content at the start of the AF process.

\section{Conclusions}

1. The specific energy consumption for pellet production was $2.0,0.20$ or $0.22 \mathrm{kWh} \mathrm{kg}^{-1}$ for wheat straw, oak leaves or leaves/straw (3:1) mixture respectively.

2. The average investigated specific biogas (methane) yield from wheat straw or oak leaves was $0.618(0.246) \mathrm{L} \cdot \mathrm{g}^{-1}$ DOM or $0.254(0.151) \mathrm{L} \cdot \mathrm{g}^{-1}$ DOM respectively.

3. Anaerobic fermentation of wheat straw gives increased specific methane yield by $62.9 \%$ compared to the specific methane yield obtained from the oak leave biomass.

4. The average biogas (methane) specific yield from the straw/leaves $(3: 1)$ mixture or straw/leaves (3:1) pellets was $0.236(0.155) \mathrm{L} \cdot \mathrm{g}^{-1}$ DOM or $0.322(0.191) \mathrm{L} \cdot \mathrm{g}^{-1}$ DOM respectively.

5. Usage of straw/leaves (1:3) pellets increases the specific methane yield by $22.3 \%$ compared to the specific methane yield obtained from non-pelletized straw/leaves $(3: 1)$ mixture.

\section{Acknowledgements}

The research was supported by a grant from Latvia University of Life Sciences and Technologies for the internal project "Studies on the effectiveness of the anaerobic fermentation process of biomass", theme G4.

\section{References}

[1] 2019. gada iesniegtās SEG inventarizācijas (1990.-2017.gads) kopsavilkums (Summary of GHG inventory (2019-2017) submitted in 2019), 24 p. (In Latvian). [online] [25.03.2020]. Available at: https://www.meteo.lv/fs/CKFinderJava/userfiles/files/Vide/Klimats/Majas_lapai_LVGMC_20 19_seginvkopsavilkums.pdf. 
[2] Rzeźnik W., Mielcarek P. Greenhouse Gases and Ammonia Emission Factors from Livestock Buildings for Pigs and Dairy Cows. Pol. J. Environ. Stud., 2016, 25(5), pp.1813-1821.

[3] Lovarelli D., Falcone G., Orsi L., Bacenetti J. Agricultural small anaerobic digestion plants: Combining economic and environmental assessment. Biomass and Bioenergy, vol. 128, 2019. 105302.

[4] Webb J., Hutchings N., Amon B., Nielsen O., Phillips R., Dämmgen U. EEA Technical report 3.F Field burning of agricultural wastes. EMEP/EEA air pollutant emission inventory guidebook., European Environment Agency, Coopenhagen, 2009, p 14 p.

[5] Rutz D., Mergner R. A Handbook, 2nd edition. WIP Renewable Energies, Munich, Germany, 2015, p 92. [online] [26.03.2020]. Available at: https://www.wip-munich.de/seawaterdesalination-conventional-and-renewable-energy-processes/1_2_Handbook-2ed_2015-02-20cleanversion.pdf.

[6] Mancini G., Esposito G. Increased biogas production from wheat straw by chemical pretreatments. Renewable Energy, vol. 119, 2018, pp. 608-614.

[7] Solé-Bundó M., Eskicioglu C., Garfí M., Carrère H., Ferrer I. Anaerobic co-digestion of microalgal biomass and wheat straw with and without thermo-alkaline pretreatment. Bioresource Technology, vol. 237, 2017, pp. 89-98.

[8] Zhong C., Wang C., Wang F., Jia H., Wei P., Zhao Y. Enhanced biogas production from wheat straw with the application of synergistic microbial consortium pretreatment. RSC Advances. 65, 2016, Issue in Progress.

[9] Dubrovskis V., Plume I., Straume I. Anaerobic co-fermentation of molasses and oil with straw pellets. Agronomy Research, 16(3), (2018). pp. 688-695.

[10] Kaltschmitt M. Methodenhandbuch, Leipzig, 2010, 93 p. (In German)..

[11]Peng X., Nges I.A., Liu J. Improving methane production from wheat straw by digestate liquor recirculation in continuous stirred tank processes. Renewable Energy, vol. 85, 2016, pp. 12-18. 